УДК 621.791.927

Д-р техн. наук В.А. Роянов (ГВУЗ

«Приазовский гос. техн. ун-m),

канд. техн. наук П.В. Коросташевский,

инже. Е.В. Сотников (ЧАО

«АЗОВЭЛЕКТРОСТАЛЬ»)

Doct. of techn. sciences V.A. Royan, cand. of techn. sciences P.V. Korostashevsky, eng. E.V. Sotnikov

\title{
ОСОБЕННОСТИ КОНСТРУКЦИИ ОБОРУДОВАНИЯ УНИВЕРСАЛЬНЫХ ЛИНИЙ СБОРКИ И СВАРКИ ЛИСТОВЫХ ПОЛОТНИЩ ОБЕЧАЕК КОТЛОВ ЖЕЛЕЗНОДОРОЖНЫХ ВАГОНОВ- ЦИСТЕРН И ТЕХНОЛОГИИ СВАРКИ ПОЛОТНИЩ В УСЛОВИЯХ СОВРЕМЕННОГО РЫНКА
}

\section{DESIGN FEATURES EQUIPMENT UNIVERSAL ASSEMBLY LINES AND WELDING OF SHEET TO WEED-NEEDY SHELLS BOILERS TANK CARS AND WELDING PANELS IN THE MARKET TODAY}

Постановка проблемы. Существующие поточно-механизированные линии для сборки и сварки листовых полотнищ обечаек котлов железнодорожных вагоновцистерн и технология сборки и сварки таких полотнищ при сборке полотнищ из листов не изменяющейся в течение длительного времени ширины работали с максимальной производительностью, сваривая одновременно все стыки. В современных условиях из-за необходимости использования листового металлопроката различной ширины работать с прежней высокой производительностью, то есть сваривать одновременно несколько стыков несколькими сварочными автоматами, практически невозможно. Это существенно снижает производительность и увеличивает время изготовления изделий, в связи с чем дальнейшее исследование технологии и оборудования для сборки и сварки указанных листовых полотнищ является важной научно-практической задачей.
Анализ последних исследований и публикаций. Линии сборки и сварки листовых полотнищ железнодорожных вагонов-цистерн и контейнеров цистерн, работающие в ПАО «Азовмаш», включают в себя стенды сборки полотнищ из листов различных параметров, автоматической стыковой сварки (под слоем флюса на флюсовых подушках) первой стороны полотнищ, автоматической сварки под слоем флюса второй стороны полотнищ, промежуточные стенды отстоя, транспортные системы и кантователь полотнищ. В конце линий располагаются вальцы, формирующие полотнище в обечайку. Полотнище на стенде сборки собирается целиком из листов и подается на стенд сварки первой стороны, затем - по технологической цепочке в стенд сварки второй стороны и, в конце линии - в вальцы (рис. 1). Стенды сварки первой и второй стороны полотнищ конструктивно выполнены для автоматической сварки всех швов каждого полотнища (как правило, 
четырех) одновременно. Это предопределяет максимальную производительность стендов сварки и линий полотнищ в целом, высокое качество сварных соединений. Такой стенд автоматической сварки первой стороны листовых полотнищ описан в публикациях [1]. Но при несовпадении ширины листов (раскроя полотнищ) с настройкой стенда, то есть с расстояниями между сварными стыками, осями электродов и флюсовых подушек соответственно, одновременная автоматическая сварка всех швов полотнища становится невозможной. В этом случае приходится выполнять сварку полотнищ путем последовательной сварки каждого стыка на одном рабочем месте, на одной флюсовой подушке (при сварке первой стороны) одним сварочным автоматом с постоянными передвижками полотнища. Несмотря на универсальность такой технологии (она совершенно не зависит от ширины свариваемых листов), при ее использовании в разы снижается производительность оборудования и выпуск продукции в целом. При этом не используется полностью дорогостоящее сварочное оборудование, простаивают сварщики. Кроме того, при сварке на одной флюсовой подушке нескольких швов подряд без промежуточной подготовки горки флюса ухудшается качество сварки последних стыков.

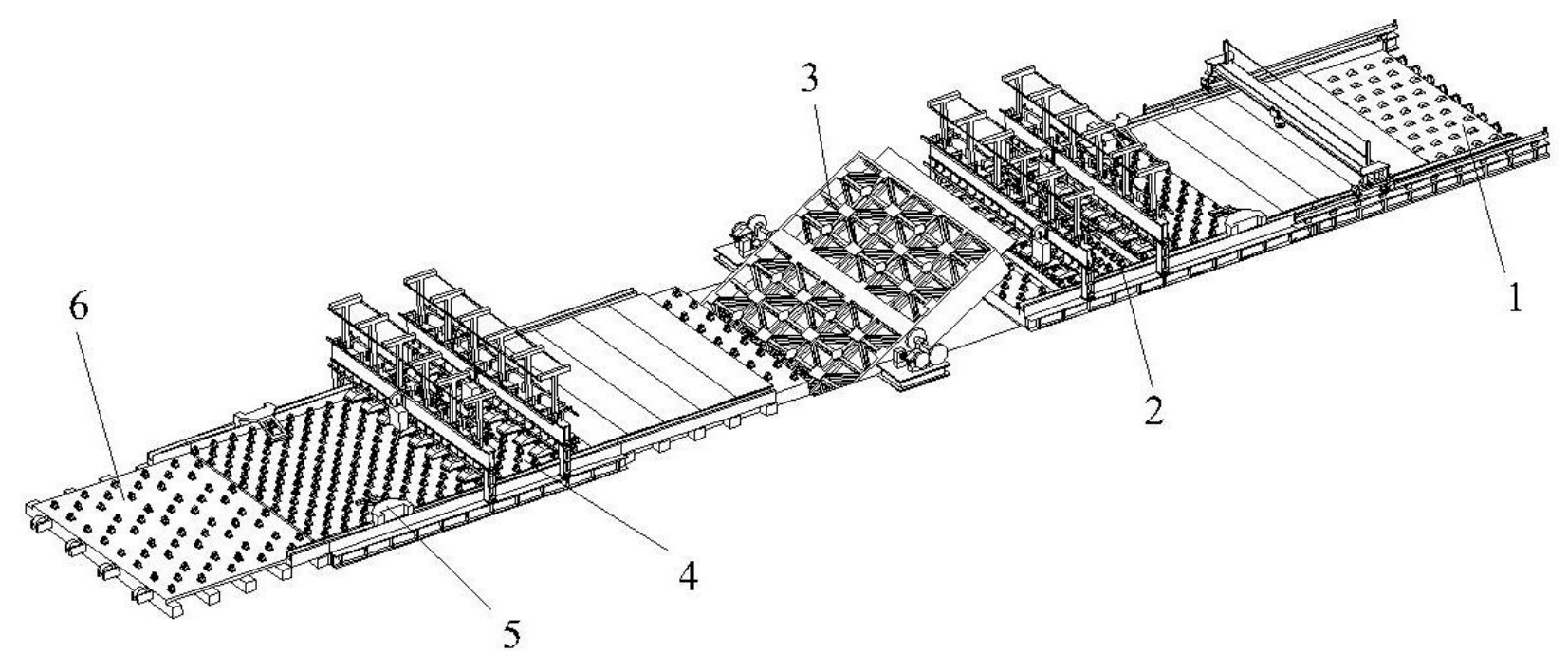

Рис. 1. Линия сборки и сварки листовых полотнищ обечаек котлов железнодорожных вагонов-цистерн и контейнеров-цистерн:

1 - стенд сборки листовых полотнищ; 2 - стенд автоматической сварки первой стороны листовых полотнищ; 3 - кантователь полотнищ; 4 - стенд автоматической сварки второй стороны листовых полотнищ; 5 - транспортирующее устройство; 6 - стенд отстоя полотнищ

При исследовании диапазона возможного изменения ширины листов полотнищ в зависимости от различных факторов в работах [2, 3] определено, что ширина листов полотнищ может быть в пределах от 1000 до 3200 мм включительно, причем любого промежуточного размера. В последнее время определяющим эту ширину фактором все чаще становится не конструктивный, а рыночный, а именно нестабильность условий приобретения и поставки листового металлопроката требуемых параметров. Из-за постоянно изменяющейся конъюнктуры рынка металлопроката предсказать ширину листов, из которых будут изготавливаться 
те или иные полотнища обечаек котлов вагонов-цистерн в то или иное время, практически невозможно. В работах [4-6] приведены основные принципы разработки, конструкция оборудования и технология сборки и автоматической сварки листовых полотнищ путем одновременной сварки четырех стыков при изменяющемся в указанных пределах раскрое. Однако сложность конструкции стенда сварки первой стороны полотнищ, в первую очередь - раздвижного роликового поля, позволяющего перестраивать расстояния по осям электродов и флюсовых подушек в зависимости от ширины листов, закрывая образующиеся при перемещении флюсовых подушек проемы и освобождая место для их передвижки, требует повышенных расходов при его эксплуатации. Такая ситуация снижает эффективность применения указанного оборудования, что не позволяет решить проблему в целом.

Цель статьи - совершенствование технологии сварки и повышение производительности оборудования поточномеханизированных линий сборки и автоматической сварки листовых полотнищ обечаек котлов железнодорожных вагоновцистерн при использовании в полотнищах листов различной ширины.

Изложение основного материала. Повысить производительность оборудования поточно-механизированных линий сборки и автоматической сварки листовых полотнищ обечаек котлов железнодорожных вагонов-цистерн в несколько раз и упростить его конструкцию при постоянно изменяющихся раскроях полотнищ представляется возможным несколькими способами.

Первый из них - это разработка технологии сварки под слоем флюса на существуюших скоростях (до $30 \mathrm{~m} / \mathrm{u}$ ) без использования каких-либо устройств для предотвращения протекания сварочной ванны (например, флюсовых подушек). В этом случае существенно упрощается конструкция универсальных стендов сварки первой стороны полотнищ [3-5], так как отпадает необходимость в стационарных и передвижных флюсовых подушках и в раздвижном роликовом поле. Стенды автоматической сварки первой и второй сторон полотнищ становятся конструктивно одинаковыми, оснащенными стационарными и передвижными порталами со сварочным автоматами и стационарным роликовым полем. Значительно упрощается также транспортная система линий. Линии в целом становятся универсальными, с относительно простой транспортной системой, и высокопроизводительными, так как на них в этом случае можно сваривать одновременно по четыре стыка на каждом полотнище любого раскроя. Перестройка стендов сварки полотнищ будет заключаться лишь в перемещении и установке порталов со сварочными автоматами по сварным стыкам.

Второй способ - это увеличение скорости непосредственно автоматической сварки под слоем флюса (на флюсовых подушках) в несколько раз с 25-30 до 100-120 м/ч. При этом для достижения максимальной производительности нынешних линий сборки и сварки полотнищ в условиях стабильных раскроев на стендах сварки полотнищ достаточно будет иметь один-два сварочных автомата и столько же флюсовых подушек на стендах сварки первой стороны. Универсальные двухместные стенды сварки преобразуются в этом случае в одноместные (рис. 2).

При достижении максимальных скоростей автоматической сварки порядка $100-120 \mathrm{M} /$ п практически отпадет необходимость во втором сварочном автомате - сварку полотнищ любого раскроя можно производить на одноместном стенде с одним сварочным автоматом на стационарном портале и одной стационарной флюсовой подушкой с передвижками полотнища. 


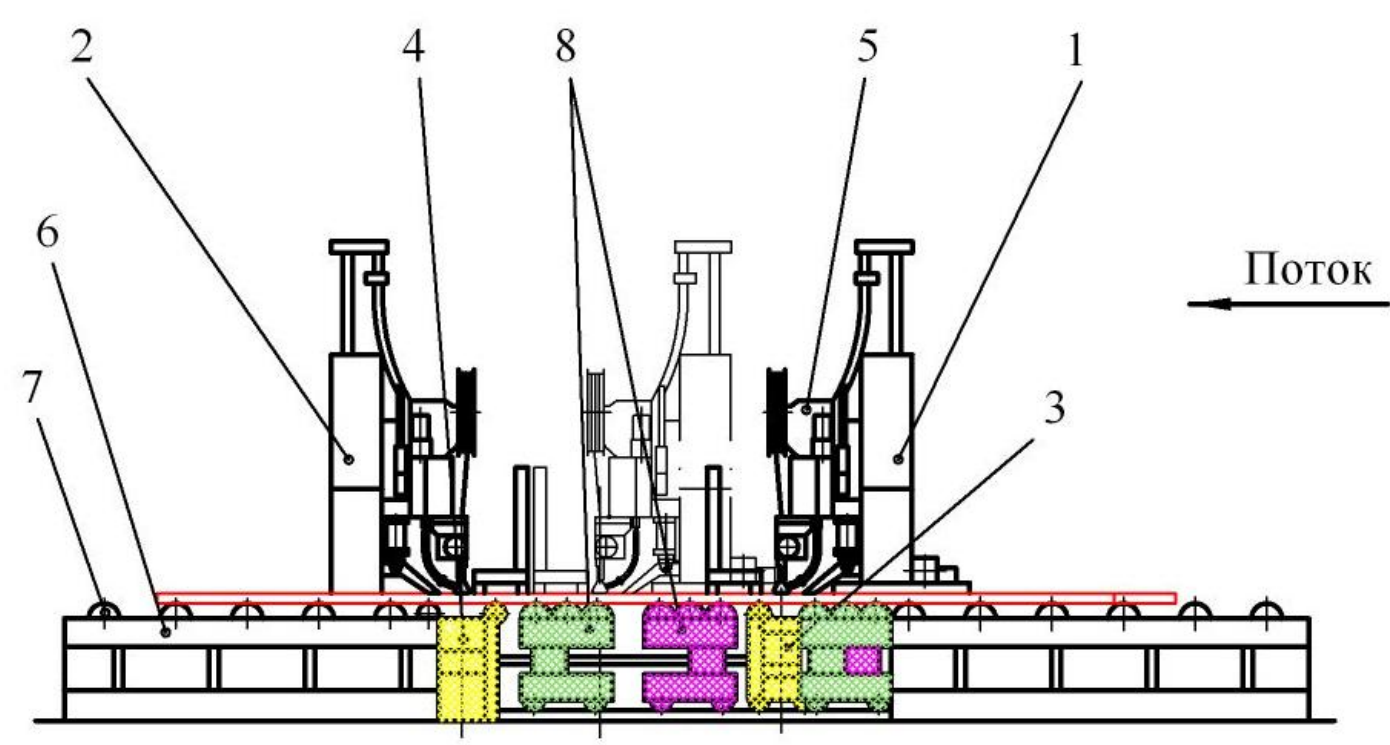

Рис. 2. Универсальный одноместный стенд автоматической сварки первой стороны листовых полотнищ:

1 - передвижной сварочный портал; 2 - стационарный сварочный портал; 3 - передвижная подъемная флюсовая подушка; 4 - стационарная подъемная флюсовая подушка; 5 - сварочный автомат; 6 - рама стенда; 7 - стационарное роликовое поле; 8 - секция передвижного роликового поля

Третий способ заключается в совмещении первого и второго, а именно в разработке технологии автоматической сварки под слоем флюса на повышенных в несколько раз (до 100-120 м/ч) скоростях без использования при этом каких-либо устройств для предотвращения протекания сварочной ванны. Это позволило бы выйти на максимальную производительности нынешних линий в условиях стабильных раскроев. Конструкция универсальных стендов автоматической сварки полотнищ в этом случае существенно упростится. Универсальные стенды автоматической сварки первой или второй стороны полотнищ будет представлять из себя стенды с одним стационарным порталом со сварочным автоматом и стационарным роликовым полем, на котором можно будет осуществлять последовательно автоматическую сварку всех стыков листовых полотнищ из листов любой ширины под слоем флюса со скоростью
100-120 м/ч. Из-за отсутствия флюсовых подушек максимально упростится транспортная система линий.

Все три способа базируются на новой технологии автоматической сварки, которая пока находится в стадии теоретической разработки и экспериментальных проверок и в ближайшем будущем еще не может быть использована в производстве. Поэтому в ПАО «Азовмаш» для увеличения производительности линий сборки и сварки листовых полотнищ при изготовлении полотнищ из листов различной ширины без перестройки сварочных стендов под каждый новый раскрой разработана технология и оборудование для одновременной автоматической сварки под слоем флюса на флюсовых подушках на существующих скоростях до 30 м/ч двух стыков двух листовых полотнищ из листов различной ширины (любого раскроя). Сварка должна осуществляться на двухместных стендах сварочными 
автоматами, установленными на каждом месте на стационарных порталах, на стационарных флюсовых подушках на стенде сварки первой стороны (рис. 3).

II место

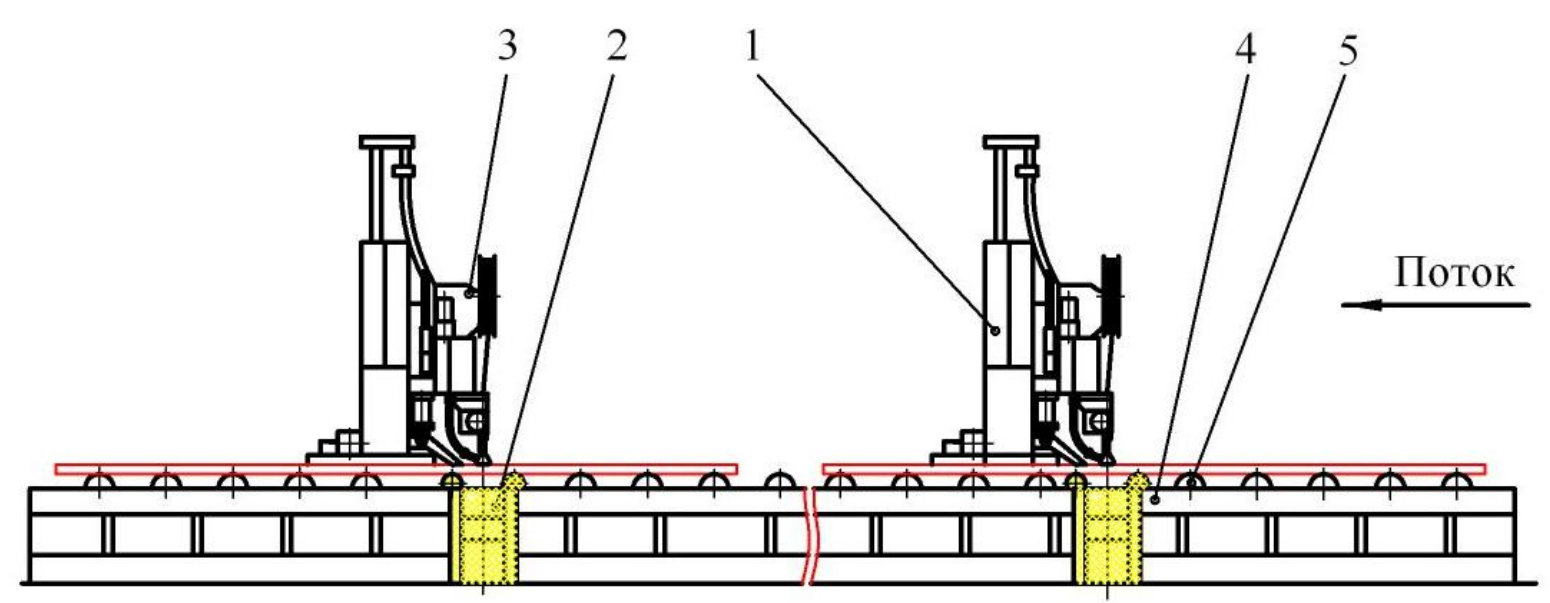

Рис. 3. Универсальный двухместный стенд автоматической сварки первой стороны листовых полотнищ:

1 - стационарный сварочный портал; 2 - стационарная подъемная флюсовая подушка; 3 - сварочный автомат; 4 - рама стенда; 5 - стационарное роликовое поле

Разработанная

автоматической сварки обеспечивает постоянную загрузку оборудования и персонала при сварке листовых полотнищ из любого количества листов, имеющих четное или нечетное количество стыков. Схема для сварки по такой технологии полотнищ из трех листов, имеющих два сварных стыка, представлена на рис. 4.

Из этой схемы видно, что сварка первого стыка полотнища производится на первом месте стенда, затем полотнище перемещается на второе место стенда, где сваривается второй стык. Во время сварки второго стыка на первом месте производится сварка первого стыка следующего полотнища.
Таким образом, обеспечивается непрерывный поток на линии. Аналогичным образом свариваются полотнища из пяти листов, имеющих четыре сварных стыка: свариваются по два стыка на каждом месте сварочного стенда (рис. 5), а также полотнища из любого нечетного количества листов с четным количеством стыков.

При этом независимо от количества сварных стыков в работе постоянно находятся по два сварочных автомата: на каждом стенде свариваются одновременно два стыка. При четном количестве листов в полотнище и, соответственно, нечетном количестве стыков сварка производится по схемам, представленным на рис. 6 и 7. 


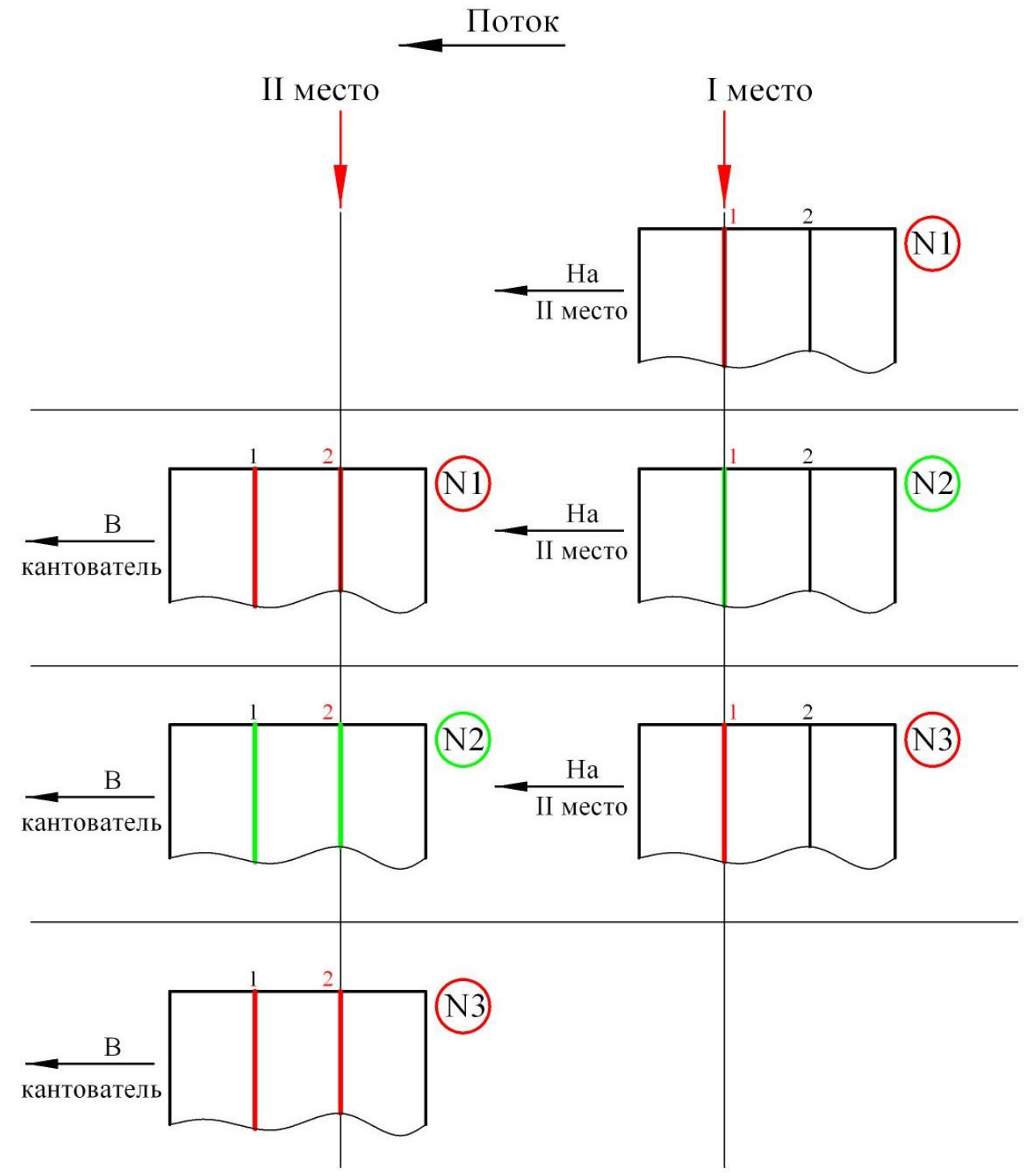

Рис. 4. Схема сварки на двухместном стенде двух стыковых листовых полотнищ:

№1 - №3 - порядковые номера последовательно свариваемых полотнищ;

1 и 2 - порядковые номера последовательно свариваемых стыков

Из этих схем видно, что на трехстыковом (четырехлистном) полотнище на первом месте свариваются два стыка (рис. 6), а после перемещение на втором месте стенда - третий. Во время сварки на втором месте стенда третьего стыка на первом месте сваривается первый стык следующего полотнища. После этого следующее полотнище перемещается на второе место стенда, где свариваются два оставшихся стыка. В это же время на первом месте производится сварка двух стыков третьего полотнища и так далее. На пятистыковом (шестилистном) полотнище сварка производится аналогичным образом: по два - три стыка на каждом рабочем месте поочередно (рис. 7). При этом, так же при сварке полотнищ с четным количеством стыков, независимо от количества сварных стыков в работе, постоянно находятся по два сварочных автомата: на каждом стенде свариваются одновременно два стыка. 


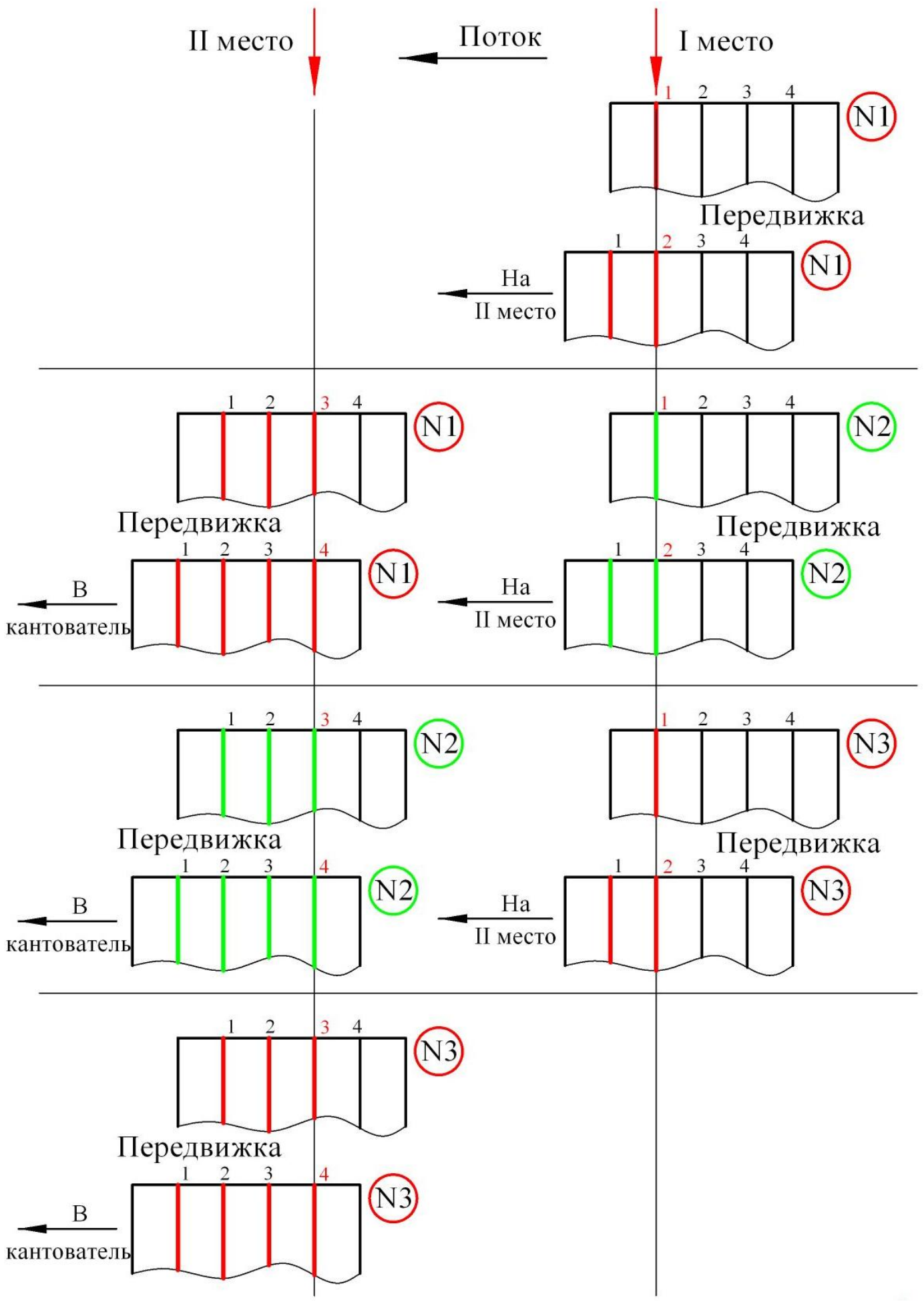

Рис. 5. Схема сварки на двухместном стенде четырех стыковых листовых полотнищ: №1 - №3 - порядковые номера последовательно свариваемых полотнищ; 1, 2, 3 и 4 - порядковые номера последовательно свариваемых стыков 


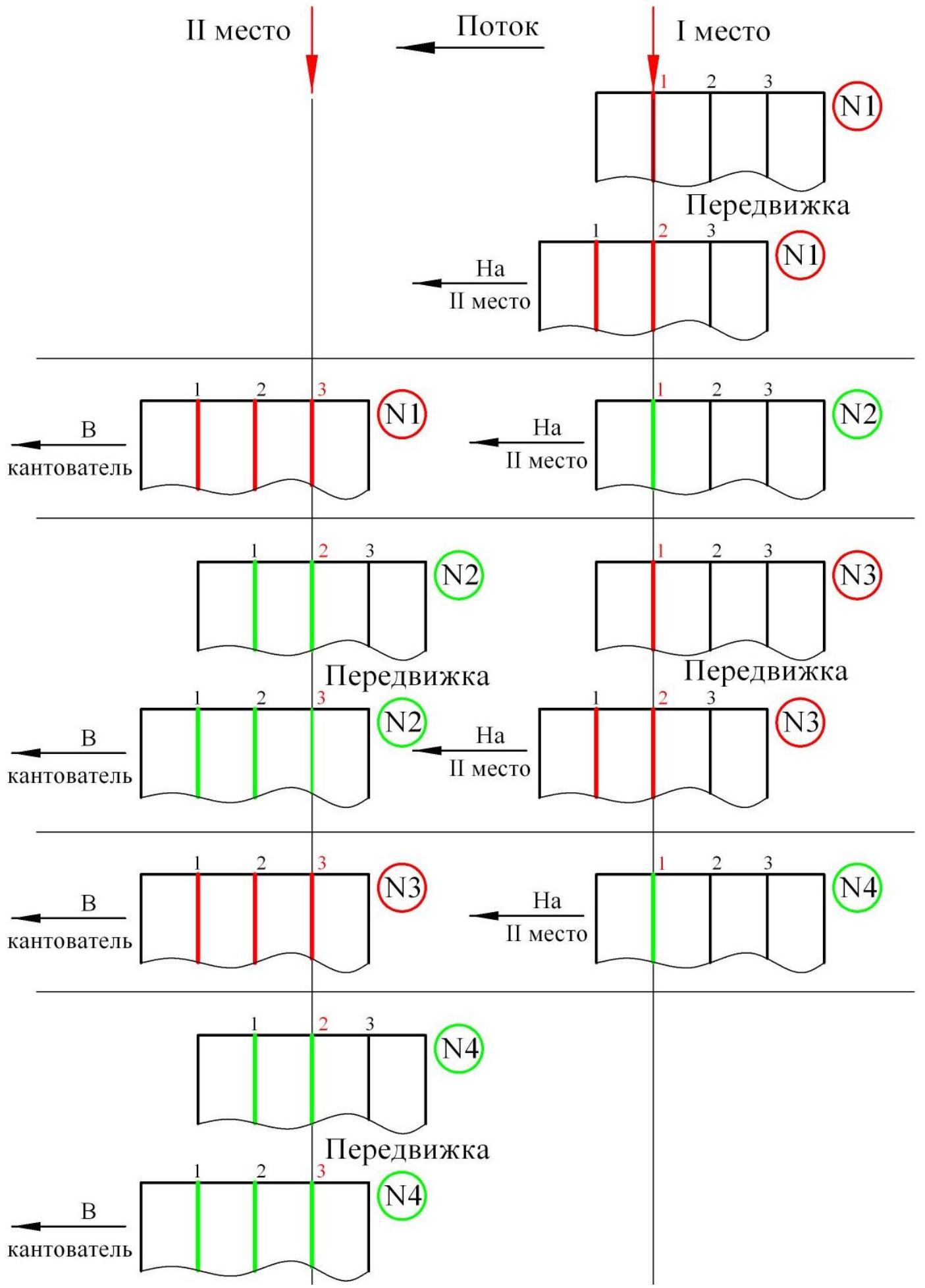

Рис. 6. Схема сварки на двухместном стенде трех стыковых листовых полотнищ: №1 - №4 - порядковые номера последовательно свариваемых полотнищ; 1, 2 и 3 - порядковые номера последовательно свариваемых стыков 


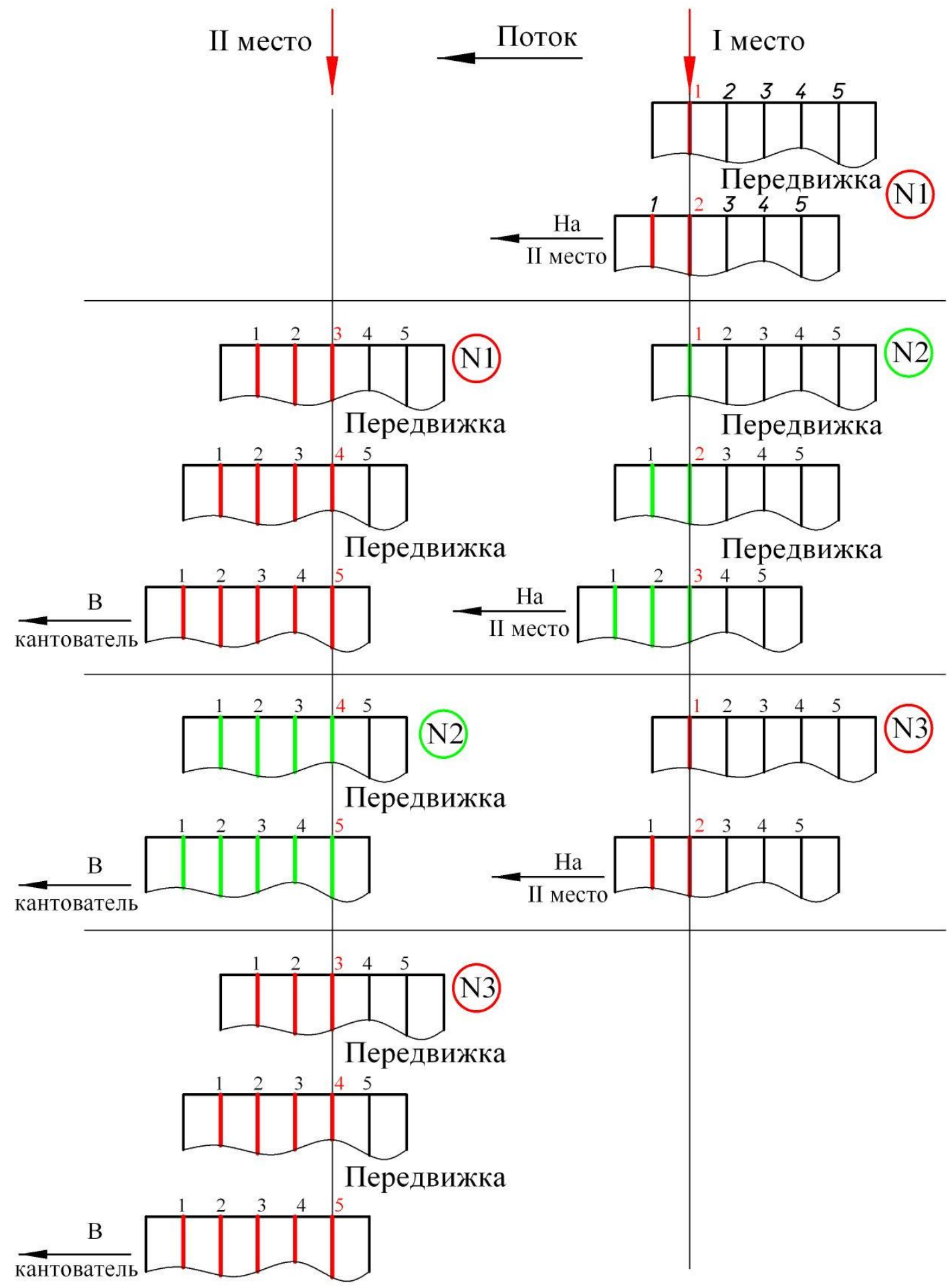

Рис. 7. Схема сварки на двухместном стенде пяти стыковых листовых полотнищ: №1 - №3 - порядковые номера последовательно свариваемых полотнищ; 1, 2, 3, 4 и 5 - порядковые номера последовательно свариваемых стыков 
Количество стыков в полотнищах, свариваемых на первом или втором рабочих местах каждого стенда, необходимо определять следующим образом.

При четном количестве стыков в полотнище количество стыков этого полотнища, свариваемых на первом $\mathrm{n}_{1 \text { чет }}$ и

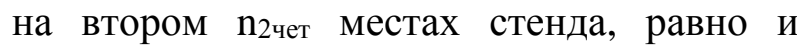
равно половине общего количества стыков $\mathrm{N}_{\text {чет: }}$ :

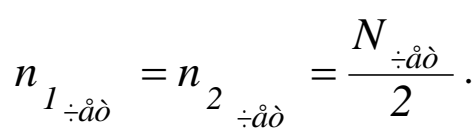

При нечетном количестве стыков в полотнище количество стыков, свариваемых на первом месте $\mathrm{n}_{1 \text { неч}}$, равно

$$
n_{1_{\text {i̊a } \div}}=\frac{N_{\text {i̊a }}-1}{2} .
$$

Количество стыков этого же полотнища, свариваемых на втором месте стенда $\mathrm{n}_{2 \text { неч}}$ равно

$$
n_{2 \text { i̊̊ }}=N_{i a ̊ \div}-n_{1 \text { i̊a }} .
$$

По выше приведенным схемам при сварке полотнища с нечетным количеством стыков количество стыков, свариваемых на первом и втором местах каждого стенда поочередно, меняется друг на друга. В случае, когда количество стыков (четное или нечетное), свариваемое на одном месте стенда, больше единицы, полотнище сваривается с передвижками.

\section{Выводы}

1. В условиях современного рынка для увеличения производительности линий сборки и сварки листовых полотнищ из листов часто изменяющейся ширины без перестройки сварочных стендов под каждый новый раскрой с обеспечением при этом постоянной загрузки оборудования и персонала необходимо использовать технологию одновременной автоматической сварки под слоем флюса двух стыков двух листовых полотнищ на двухместных стендах сварочными автоматами, установленными на стационарных порталах, на стендах сварки первой стороны полотнищ - на стационарных флюсовых подушках.

2. Для существенного повышения производительности оборудования поточно-механизированных линий сборки и автоматической сварки листовых полотнищ обечаек котлов железнодорожных вагонов-цистерн при использовании в полотнищах листов различной ширины и упрощения конструкции стендов автоматической сварки необходимо проведение дополнительных исследований и разработка новых технологий автоматической сварки под слоем флюса:

- на существующих скоростях (до 30 м/ч) без использования каких-либо устройств для предотвращения протекания сварочной ванны (флюсовых подушек и т. п.);

- на повышенных (до 100-120 м/ч) скоростях с использованием устройств для предотвращения протекания сварочной ванны;

- на повышенных скоростях без использования каких-либо устройств для предотвращения протекания сварочной ванны.

Разработка таких технологий является перспективным направлением, реализация которого позволит увеличить выпуск продукции вагоностроения на более простом специальном технологическом оборудовании с меньшими затратами.

\section{Список литературы}

1. Коросташевский, П.В. Стенд автоматической сварки листовых полотнищ [Текст] / П.В. Коросташевский // Сварочное производство. - 1991. - №3. - С. 26-27. 
2. Коросташевкий, П.В. Выбор основных параметров стендов автоматической сварки листовых полотнищ обечаек котлов в крупносерийном производстве [Текст] / П.В. Коросташевский // Вісник Приазовського державного технічного університету. Маріуполь, 2006. - №16. - С.171-175.

3. Коросташевский, П.В. Совершенствование принципов проектирования универсального технологического оборудования линий сборки и сварки листовых полотнищ [Текст]: автореф. дисс... канд. техн. наук: спец. 05.03.06 / П.В. Коросташевский. Мариуполь, 2010. - 20 с.

4. Установка для зварювання листових полотнищ [Текст]: Пат. 32090, Україна, МПК В23К 37/04 / П.В. Коросташевський, В.О. Роянов, С.П. Нікітченко, І.В. Готовченко. № u 2007 09907; заявл. 04.09.2007; опубл.12.05.2008; Бюл.№9. - 2 с.

5. Потокова механізована лінія для складання й зварювання листових полотнищ [Текст]: Пат.61072, Україна, МПК В23К 37/04 / П.В. Коросташевский, В.О. Роянов. № u 2010 14473; заявл. 03.12.2010; опубл.11.07.2011; Бюл.№13. - 3 с.

6. Роянов, В.А. Принципы конструирования оборудования транспортных систем универсальных линий сборки и сварки листовых полотнищ [Текст] / В.А. Роянов, П.В. Коросташевский // Вісник Донбаської державної машинобудівної академії. Краматорськ, 2010. - №2(19). - С. 245-250.

Ключевые слова: линия сборки и сварки листовых полотнищ, автоматическая сварка, ширина листов, универсальное оборудование, производительность оборудования.

\section{Аннотации}

В умовах сучасного ринку для збирання та зварювання листових полотнищ обичайок котлів залізничних вагонів-цистерн змушені використовувати листи різної ширини незалежно від моделі вагона. Встановлено, що це знижує продуктивність обладнання. Розглянуто перспективні варіанти технології та обладнання, збільшуючи продуктивність ліній. Запропоновано та досліджено практичні варіанти технології та універсального обладнання для зварювання листових полотнищ у діючому виробництві 3 підвищеною продуктивністю.

В условиях современного рынка для сборки и сварки листовых полотнищ обечаек котлов железнодорожных вагонов-цистерн приходится использовать листы различной ширины независимо от модели вагона. Установлено, что это снижает производительность оборудования. Рассмотрены перспективные варианты технологии и оборудования, увеличивающие производительность линий. Предложены и исследованы практические варианты технологии и универсального оборудования для сварки листовых полотнищ в действующем производстве с повышенной производительностью.

Under the up-to-date market conditions for the assembling and welding the railway tankswagon tanks shells sheet panels the sheets of the different breadth in spite of the wagon model forced to be used. It is determined, that the equipment productivity is fall of this. The increase lines productivity perspective variants of the technology and the equipment are considered. The practice variants of the technology and the welding sheet panels at the working production with increased productivity universal equipment are proposed. 